\title{
Alteridade e embrião humano: o rosto como exigência ética de acolhimento do outro
}

\author{
Otherness and human embryo: the face \\ as ethics demand host of other
}

\section{Marcos Alexandre Alves ${ }^{[a]}$, Edson Sallin ${ }^{[b]^{*}}$}

[a] Centro Universitário Franciscano, Santa Maria, RS, Brasil

[b] Centro Universitário São Camilo, São Paulo, SP, Brasil

\section{Resumo}

Discutiremos neste artigo, os temas da alteridade e do embrião humano. A partir do ponto de vista ético, mostraremos que o embrião humano é portador de um sentido, possui um rosto que carece proteção e acolhimento em sua condição existencial. Dividimos o artigo em três pontos: inicialmente, apresentamos o embrião como possuidor de vida desde a sua concepção, momento em que se estabelece o instante da existência da humana. Posteriormente, refletimos sobre a categoria rosto como exigência ética que expressa o imperativo "tu não matarás", segundo a perspectiva do

* MAA: Doutor em Filosofia da Educação, e-mail: maralexalves@gmail.com

ES: Especialista em Bioética, e-mail: idsallined@yahoo.com.br 
filósofo Emmanuel Lévinas. Por fim, defendemos que o embrião humano, dado à sua condição de vulnerabilidade, manifesta a desmedida do outro enquanto outro, isto é, a alteridade absoluta que necessita e suplica acolhimento responsável e incondicional.

Palavras-chaves: Embrião humano. Vida humana. Rosto. Alteridade.

\section{Abstract}

In this article, we will discuss the themes of otherness and of the human embryo. From the ethical point of view, we show that the human embryo carries absense, has a face that needs protection and care in their existential condition. We divide the article into three points: first, we present the embryo as having life from conception, when it comes down to the moment of human existence. Later, reflecting on the category face as ethical requirement that expresses the imperative "thou shall not kill", according to philosopher Emmanuel Levinas's perspective. Finally, we argue that the human embryo, given their vulnerable condition, expresses the inordinate other as other, ie, the absolute otherness that begs needs and responsible acceptance and unconditional.

Keywords: Human embryo. Human life. Face. Otherness.

\section{Introdução}

Discutiremos neste artigo, em âmbito reflexivo-crítico, o tema do embrião humano. A partir do ponto de vista ético, mostraremos que o embrião humano é portador de um sentido, possui um rosto que carece ser protegido e acolhido em sua condição existencial. Ou seja, o presente artigo tem por finalidade discutir o tema da Alteridade do embrião humano, ou seja, falar sobre vida em plenitude. Assim, a pergunta de fundo que mobiliza a nossa reflexão neste artigo é: o embrião humano, na sua existência tem um rosto?

$\mathrm{O}$ artigo se divide em três pontos: inicialmente, apresentamos o embrião humano como marco da vida, momento em que se estabelece o 
instante da existência da humana, pois ela já existe em plenitude. Para um melhor entendimento do tema, posteriormente, refletimos sobre a categoria rosto como exigência ética que expressa o mandamento maior "tu não matarás", segundo a perspectiva do filósofo contemporâneo Emmanuel Lévinas. Por fim, defendemos que o embrião humano, dado à sua condição de vulnerabilidade, manifesta a desmedida do outro enquanto outro, isto é, a alteridade absoluta que necessita e suplica o acolhimento responsável e incondicional.

A intenção é apresentar o embrião humano como rosto, através do qual a sua alteridade absoluta se manifesta, em si e por si, como existente humano e pessoa na sua total onipotência. No rosto, cada existente humano expressa a sua existência única e verdadeira. Somos únicos e irrepetíveis na existência, por isso o embrião desde o instante da sua existência é e deve ser considerado existente humano, pessoa e não outra coisa. Além de expressar a singularidade do humano, o rosto manifesta a exigência ética maior: "tu não matarás", ou seja, que em nenhum momento o embrião pode e/ou deve ser destruído, senão acolhido. $\mathrm{Na}$ condição existencial do embrião resplandece uma alteridade, ainda desconhecida é verdade, mas que existe e simboliza a experiência concreta do outro enquanto totalmente outro que reclama hospitalidade e não hostilidade.

\section{Embrião humano: marco da existência}

O fato de a sociedade colocar a vida humana no centro e/ou como ponto de partida para se pensar o sentido do humano, nos instiga compreender o seu valor e o que isso representa, pois a vida "grita" por ser respeitada desde seu início, como sagrada e de valor absoluto. Todo ser humano, merece respeito, proteção e ser valorizado como pessoa e não como objeto. Neste meio, está o embrião humano, como pessoa, ser humano, que tem vida e dignidade de viver.

O início da vida começa na concepção, onde já existe um existente humano, uma pessoa com todas as potencialidades humanas, pois "que a vida começa com a fecundação é um fato científico com demonstração experimental; não se trata de um argumento metafísico ou de uma hipótese 
teológica" (CIPRIANI, 2007, p.59). Porém, estamos inseridos num tempo de mudanças culturais, tecnológicas e morais. Assim, a compreensão do sentido vida humana, vai para o mesmo caminho. Para Salzano, "vivemos em uma época de mudanças vertiginosas. Essas mudanças estão condicionando o surgimento de questões éticas inimagináveis há apenas poucos anos. É dever nosso estarmos atentos a essas modificações, pautando nossa conduta de maneira ética e responsável" (SALZANO, 1998, p.59).

Vivemos numa sociedade ${ }^{1}$ que prioriza cada vez mais uma cultu$\mathrm{ra}^{2}$ da morte ${ }^{3}$, em detrimento da cultura da vida. Ora, a vida perde valor, sentido e dignidade. Segundo Junges, "numa sociedade como a brasileira, na qual a vida vale pouco e está continuamente ameaçada pela morte em suas mais variadas manifestações, é necessário lutar pela qualidade de vida, pelo direito de viver com dignidade" (1999, p.114). Neste sentido, essa cultura ${ }^{4}$ é responsável pela eliminação de vidas, gerando uma mentalidade reducionista e fragmentada. Neste mesmo sentido, Maçaneiro afirma que existe,

Uma morte gerada por mecanismos inclusive conscientes. Mecanismos que matam dentro e fora da ordem institucional. Localizar essa morte, ou melhor, localizar os sujeitos que morrem é um passo importante para descobrir a quem deve se orientar, prioritariamente, a defesa dos direitos humanos (MAÇANEIRO, 2003, p.61).

Durante décadas, no decorrer de nossa história, o conceito de início da vida esteve presente nos campos das ciências médicas biológicas,

10 papa Bento XVI na encíclica Caritas in Veritate, fala deste tipo de sociedade que nega a vida, segundo ele "quando uma sociedade começa a negar e a suprimir a vida, acaba por deixar de encontrar as motivações necessárias para trabalhar a serviço do bem do homem" (CV, n.28).

2 A cultura atual tende a propor estilos de ser e viver contrários à natureza e dignidade do ser humano. 0 impacto dominante dos ídolos do poder, da riqueza e do prazer efêmero se transformaram acima do valor da pessoa, em norma máxima de funcionamento e em critério decisivo na organização social (DA, n. 387).

30 esfacelamento da fraternidade/solidariedade, de um lado, e a sacralização da economia de mercado, de outro, criaram aos poucos o que hoje chamamos de "cultura da Morte." É a triste realidade de uma morte cultivada (MAÇANEIRO, 2003, p.60).

4 A cultura contemporânea vê no ser-para-a-morte um forte atrativo porque o Nada da morte oferece certa comodidade. Ele suscita um horizonte de sentido e um projeto em que tudo pode ser construído em função da lógica do Ser. Bem ao contrário, no ser-para-a-vida a condição humana da natalidade (ARENDT, 2002, p.191). 
filosóficas e teológicas, apresentando assim, peculiaridades e noções fundamentais para a construção do conceito de pessoa. Afinal, o embrião é ou não um ser humano? Em que medida pode ser considerado pessoa?

Frente a essas questões, muito já foi discutido, pesquisado e argumentando, porém continuam em aberto e impõem um grande mistério para a ciência. O embrião humano, o grande marco da vida, ${ }^{5}$ desde a sua origem com a concepção ${ }^{6}$, deve ser visto como existente humano que tem total dignidade e valor. $\mathrm{O}$ embrião humano deve ser reconhecido como uma pessoa, com todas as suas potencialidades de humano. Logo, a eliminação da vida, é um crime contra um ser vulnerável e indefeso. João Paulo II, na Evangelium Vitae diz que o resultado de tudo isto é dramático:

Se é muitíssimo grave e preocupante o fenômeno da eliminação de tantas vidas humanas nascentes ou encaminhadas para o seu ocaso, não o é menos o fato de à própria consciência, ofuscada por tão vastos condicionalismos, lhe custar cada vez mais a perceber a distinção entre o bem e o mal, precisamente naquilo que toca o fundamental valor da vida humana (EV, n.04).

A vida humana é um processo coordenado, que desde o instante da concepção já é precisa ser concebida como pessoa, ou seja, não se trata apenas um aglomerado de células, senão de vida e vida em plenitude. Para Antônio Moser, a vida é:

Um continuum, e a única aparente descontinuidade, ao longo do processo evolutivo de um ser humano, verifica-se durante o processo de fertilização, em especial após a singamia, na qual dois elementos biológicos distintos, com diferentes patrimônios genéticos, se fundem num único elemento que, este sim, se desenvolverá progressivamente até o nascimento (2004, p.157).

5 A vida como fonte é mais rica que o rio de suas ações; e a meta, o fim último, transcende sempre cada passo realizado, pois os fins particulares não realizam o último, que é o Bem tout court, a plenitude da felicidade. Isso significa que, se uma pessoa pode privar de um bem particular, não pode ser privada nem privar-se do Bem último nem da tensão para o próprio bem (SGRECCIA, 1996, p.141).

6 A vida humana começa na fertilização, quando espermatozóide e óvulo se encontram e combinam seus genes para formar um indivíduo com um conjunto genético único. Assim é criado um novo indivíduo, um ser humano com direitos iguais aos de qualquer outro (BARCHIFONTAINE, 2010, p.43). 
Quando se discute sobre o início da vida, depara-se diante de vários pressupostos, especialmente, sobre o momento em que se inicia o ciclo vital. A vida perde seu mistério e sentido, quando não valorizamos a mesma desde o instante da sua concepção. São muitas as ameaças cometidas contra o valor inviolável da vida. O papa João Paulo II, na encíclica Evangelium Vitae, fala sobre as atuais ameaças à vida humana:

Hoje, este anúncio torna-se particularmente urgente pela impressionante multiplicação e agravamento das ameaças à vida das pessoas e dos povos, sobretudo quando ela é débil e indefesa. Às antigas e dolorosas chagas da miséria, da fome, das epidemias, da violência e das guerras, vêm se juntar outras como modalidades inéditas e dimensões inquietantes (EV, n.03).

A vida humana deve ser respeitada, protegida e amada desde o seu início. Portanto, qualquer existente humano deve ter seu direito reconhecido como pessoa mesmo antes de nascer. O Catecismo da Igreja Católica, quando trata do tema do embrião humano, diz o seguinte: "visto que deve ser tratado como pessoa desde a concepção, o embrião deverá ser defendido em sua integridade, cuidado e curado, na medida do possível, como qualquer outro ser humano" (CAT, n. 2273).

Por conseguinte, o embrião humano não pode ser visto como coisa ou algo semelhante, mas sim, como pessoa que tem todos os direitos de nascer. Ao pressupormos a sua existência, estaremos argumentando que ele existe e, logo, é um ser como os demais. Na realidade possui uma individualização, uma existência única e verdadeira. Frente a isso, Marciano Vidal afirma que:

A este dado, de fato hoje evidente, se contrapõe, não obstante, desde muitas partes, a afirmação segundo a qual o embrião inicial possui, certamente, uma individualidade genética, mas não uma identidade multicelular e, por conseguinte, no sentido antogenético, poder-se-ia qualificar o embrião inicial como pró-indivíduo. Dito com outras palavras: individualidade genética e individualidade pessoal deveriam ser distintas. Somente quando existisse um organismo humano viável, será possível também ser pessoa (VIDAL, 1997, p.150). 
A vida humana ${ }^{7}$ não é fruto do acaso ou produto de manipulação, mas nasce fruto do amor entre Deus e a humanidade. Por isso, todo ser humano deve ser respeitado, mesmo antes de nascer. Nesse sentido, para Bourguert, "isso não é uma visão reducionista: o ser humano atravessa as diferentes ordens da realidade, do elementar até o completo e até a consciência, e é essa trajetória ascendente que percorre, e que define, sua individualidade" (2002, p.59). No marco de sua existência, o embrião como qualquer outro existente humano, necessita de proteção e amparo. Toda e qualquer vida deve ser respeitada, amada e aceita. Eliminar a vida de um existente humano em gestação é antes de tudo destruir a sua história, a sua condição de pessoa, que ocupa um lugar. Para Palazzani, se existe discussões sobre a definição filosófica de pessoa e também sobre a identificação do início da vida pessoal, parece impossível que "haja qualquer dúvida a respeito do início da vida biogenética do ser humano, já que, sendo o ser humano espécie vivente de homo sapiens, o início de sua vida deveria coincidir com a união dos gametas humano-masculino e feminino" (PALAZZANI, 1996, p. 41-42).

Portanto, o embrião é um existente em sua total plenitude de se realizar como humano, porém, dada a sua fragilidade precisa ser cuidado, protegido e acolhido, somente assim irá constituir uma identidade pessoal, única e verdadeira.

\section{Alteridade: o rosto do embrião humano}

Todo existente humano possui alteridade ${ }^{8}$. Ou seja, como humanos, existimos e somos rosto. Possuir rosto significa a condição a partir da qual a alteridade pode ser expressar, enquanto única e irrepetível.

7 Toda vida humana tem um valor fundamentalmente igual. Toda vida humana possui a mesma dignidade. Toda vida humana se faz credora da mesma proteção. Toda discriminação é uma incoerência. Toda vida humana é um valor fundamental, embora não absoluto (BENTO, 2008, p.219).

8 Na medida em que o homem parece mais sem projetos e sem esperar nada de si e de ninguém, a alteridade poderá revelar-se não como aquela que culpabiliza, que condena, que impõe através de aparato legal, mas como vulnerabilidade na pequena palavra que sai do seu corpo. Ela revela a nudez e a fragilidade do outro em seu dar-se e retirar-se" (LÉVINAS, 1994, p.67). 
Ademais, tal como a alteridade se expressar mediante o rosto, podemos nos questionar se o embrião teria um rosto? Poderíamos identificá-lo como um existente com um rosto? Se o embrião é uma pessoa, com todas as suas potencialidades, o seu rosto já estaria expresso na sua própria existência? Se ele não teria um rosto desde o seu início, como então, poderíamos expressar o mesmo depois?

$\mathrm{Na}$ perspectiva levinasiana, podemos afirmar que desde o instante da sua concepção, o embrião possui um rosto, que o identifica enquanto tal. Por isso, o rosto é a marca característica que identifica o existente humano e o coloca em relação com o outro. Possuir um rosto é a condição de possibilidade para se expressar o que se é, construir a sua própria uma história e se relacionar com os demais existentes humanos. Nesse sentido, segundo Lévinas "o que vive na totalidade existe como totalidade, como se ele ocupasse o centro do ser e fosse sua fonte, como se tirasse tudo do aqui e do agora, onde, contudo, ele está posto ou criado" (LÉVINAS, 2010, p.33).

Assim, o que existe, existe pela sua onipotência, pela sua totalidade de ser, um ente que tem um rosto, e essa condição o coloca em relação com outrem, por isso, "a relação do eu com a totalidade é uma relação com os seres humanos dos quais reconheço o rosto" (LÉVINAS, 2010, p.37). O outro está sempre em relação com eu - outra existência. Neste sentido, o embrião tem uma relação com outrem, pela sua existência única e verdadeira, cujo "modo de ser e de se manifestar consistem em voltar sua face para mim, em ser rosto” (LÉVINAS, 2010, p.43). O embrião humano, está em relação com a totalidade do outro e a sua alteridade é o rosto.

Para Lévinas, o rosto "não é absolutamente uma forma plástica como um retrato; a relação ao Rosto é, ao mesmo tempo, relação ao absolutamente fraco ao que está absolutamente exposto, o que está nu e o que é despojado, é a relação com o despojamento [...]" (LÉVINAS, 2010, p.131). Em si, o rosto representa a totalidade do ser humano, sua integra relação com outro. O rosto, segundo o autor, é o não matarás, isto é, o respeito e o cuidado com o outrem. "É no Rosto do Outro que vem o mandamento que interrompe a marcha do mundo [...] o Rosto do 
Outro, tomado por uma imagem entre imagens e quando a Palavra de Deus que ele carrega fica desconhecida" (LÉVINAS, 2010, p.137).

$\mathrm{Na}$ realidade, quando enfatizamos que o embrião tem um rosto queremos afirmar que ele possui uma existência própria e única. Ele é Outro que se revela como alguém que tem uma alteridade, uma história e uma forma própria de manifestar a sua humanidade.

No rosto o expressado assiste à expressão, expressa sua própria expressão, permanece sempre dono do sentido que ele mesmo dá. Ato puro à sua maneira, ele se nega à identificação, não entra no já conhecido e dá, como diria Platão, assistência a si mesmo, isto é, fala. A epifania do rosto é toda ela linguagem (LÉVINAS, 1988, p.173).

O embrião humano existe enquanto singularidade única e verdadeira (vulnerabilidade). Em seu rosto, o embrião manifesta a condição extrema de uma alteridade vulnerável que exige acolhimento e responsabilidade. Logo, não pode ser tratado como coisa ou algo parecido, mas sim como existente humano, pois o seu rosto não só suplica cuidados, mas também demanda reverência e respeito.

\section{Alteridade e embrião humano: acolhimento e responsabilidade}

A vida humana é valiosa ${ }^{9}$, e desde o momento da concepção merece respeito, proteção e cuidado. $O$ existente humano ${ }^{10}$ é digno de nascer e participar da sociedade. A vida tem dignidade quando é respeitada desde a sua origem. A dignidade ${ }^{11}$ da vida nasce do fato de ela ser

90 valor da vida humana precisa ser exposto de modo fundamental, vale dizer, justificado em sua raiz (VIDAL, 1997, p.74).

100 homem é a única criatura terrestre que Deus ama por si mesma. Na criação do homem, Deus "pensa" em algo totalmente diferente de toda e qualquer outra criatura visível e, portanto, em um "alguém" especial. 0 homem é homem porque é imagem de Deus (CIACCIA, 1994, p.54).

11 Para Netto dignidade indica, "o valor singular e a grandeza da pessoa que, Segundo a concepção bíblica, têm como fundamento sua proveniência de Deus, o fato de ter sido feita a sua "imagem e semelhança" e de ter o próprio Criador como fim. É à força dessa identidade que todo ser humano, sem distinção de idade, sexo, condição social, posição ideológica, sendo por isso sujeito de direitos inalienáveis" (NETTO, 2003, p.198). 
inviolável ${ }^{12}$, por isso qualquer existente humano é digno não importando a sua condição. "Essa dignidade da pessoa estende-se, finalmente, ao embrião e ao cadáver, mesmo que agora as aparências com a pessoa não existam, ou não existam mais" (DURAND, 2007, p.308).

O embrião é outro existente humano, que tem dignidade como qualquer outra pessoa. Por isso, ele é Outrem que tem vida, que existe e interagem com os demais na sua total potencialidade e alteridade. Tratar o embrião como um existente humano é entender que o mesmo existe, tem vida e ocupa lugar um lugar. "Compreender o ser enquanto ser é existir” (LÉVINAS, 2010, p.22). Ou seja, o ser é ser quando há uma relação com outrem, visto que "eu compreendo o ser em outrem, além de sua particularidade de ente; a pessoa com a qual estou em relação, chamo-a ser, mas, ao chamá-lo ser, eu a invoco" (LÉVINAS, 2010, p.27).

Por conseguinte, a vida humana desde a sua origem é sagrada, um bem valioso e absoluto em sua alteridade. Desse modo, é preciso colocar em ação todos os meios possíveis para proteger e prolongar a vida, mesmo que diminuída. A saber, o embrião tem valor ${ }^{13}$ e dignidade. Segundo Sanches “[...] é necessário defender a máxima extensão factual da dignidade humana que reside no existir como membro da espécie humana, ou seja, negando a dignidade a um ser da espécie humana, nega-se a dignidade a um ser humano, integralmente" (2009, p.105).

Encontramos aqui o verdadeiro sentido de que o embrião humano é Outrem, possui um rosto ${ }^{14}$, mesmo que não o vemos. Esse Outrem tem existência própria, mesmo dependendo do útero materno, possui vida como qualquer outra pessoa. Logo, precisa ser respeitado, amado

${ }^{12}$ A vida humana é sagrada e inviolável em cada momento da sua existência, inclusive na fase inicial que procede o nascimento. Desde o seio materno, o homem pertence a Deus que tudo perscruta e conhece, que forma e plasma com suas mãos, que vê quando ainda é pequeno embrião informe, e que nele antevê 0 adulto de amanhã, cujos dias estão contados e cuja vocação está já escrita no livro da vida (EV, n.61).

${ }^{13}$ É necessário afirmar que um ser humano tem valor moral, independente de sua capacidade de fazê-lo valer, ou ter consciência da sua dignidade, isto sem negar a importância da autoconsciência e liberdade, como elementos fundamentais da pessoa (SANCHES, 2009, p.109).

${ }^{14}$ A relação como o rosto, acontecimento da coletividade-palavra- é relação com o próprio ente, enquanto puro ente (LÉVINAS, 2010, p.31). 
e protegido, e em nenhum momento poderá ser destruído ${ }^{15}$. Negá-lo, é negar a sua alteridade. Segundo Lévinas, o rosto que me olha me afirma, mas

Face a face, não posso mais negar o outro: somente a glória numeral do outro torna possível o face a face. O face a face é assim uma impossibilidade de negar, uma negação da negação. A dupla articulação desta fórmula significa concretamente: o "não cometerás homicídio" se inscreve no rosto e constitui sua própria alteridade (2010, p.57).

Desde o seu início o embrião ${ }^{16}$, como pessoa, ${ }^{17}$ existe e merece todo o respeito e proteção. Ele é realmente aquilo que é, e não outra coisa. Ou seja, o indivíduo desde a fecundação, já é - mas em escala menor - tudo o que ele está destinado a tornar-se em escala maior no final mais avançado de seu desenvolvimento. Se ele é um ser humano em seu nascimento, como todos concordam, ele é também no primeiro instante de sua vida fetal, pois ele não faz senão, nesse intervalo, tornar-se o que ele é, e o que ele permanece até o dia de sua morte.

Na sua singularidade como humano, o embrião é Outrem que tem um código genético, uma face, um rosto. É humano e pessoa, na forma e na concretude de ser humano. Não pode ser compreendido de outra forma, senão como o que realmente é: existente humano e pessoa.

15 Quando manipulamos a vida, não manipulamos só algo ou alguém que virá, mas manipulamos o que fomos, somos e seremos. Somos seres de símbolos. A manipulação está prenhe de significação por conjugar em si o caráter técnico-poiético e o caráter linguístico da poésis. Por isso que ela tem sempre um caráter de irreversibilidade (ARENDT, 2002, p.248).

${ }^{16} 0$ embrião pertence à espécie biológica humana que se não for desde 0 início verdadeiramente indivíduo humano, não poderia levar a ser sucessivamente sem contradizer a identidade de sua essência (LUCAS, 2001, p.77).

17 Por isso, ao considerar a pessoa humana como fundamento de um modelo ético como na bioética personalista, se enfrenta a realidade com precisão, e parte-se dessa entidade (unidade de corpo-espírito) como parâmetro para ditar a prática da bioética. Assim, a dignidade de todo ser humano é certamente respeitada (RAMOS, 2009, p.74). 


\section{Considerações Finais}

O conceito de que o embrião é existente humano e pessoa, é fundamental no âmbito da biociência, biotecnologia e bioética. Muitas são as teorias utilizadas para definir em que momento se dá o início da vida humana. Amparados no pensamento de Lévinas, defendemos que o embrião é uma alteridade absoluta, que tem um rosto, na qual resplandece a sua existência, única e verdadeira. Definir em que momento se dá o início da uma nova vida será decisivo para determinar, por exemplo, que o aborto é um crime contra a vida humana.

A nossa intenção foi trazer à tona um assunto importantíssimo e necessário, em uma sociedade voltada para a cultura da morte, onde a vida é rechaçada ao esquecimento. Quando o embrião é concebido como detentor de um rosto, deixa de ser visto como coisa, objeto, para ser aceito como existente humano na sua alteridade. Se a vida tem um ponto inicial, podemos dar um passo mais distante, isto é, de que desde o instante da sua existência podemos falar de pessoa humana, vida humana.

Para finalizar, entendemos que o embrião além de ser humano e pessoa, é outro que existe, isto é, alteridade. Ele é outro em nossa vida, alguém que tem valor, dignidade e importância. Em nenhum momento a vida humana poderá ser desvalorizada ou aniquilada. Portanto, é dever e obrigação das instituições promover uma cultura da vida, que tem como ponto de partida a sua defesa em todas as dimensões.

\section{Referências}

ARENDT, H. A condição humana. Rio de Janeiro: Forense Universitária, 2002.

BOUGUERT, V. O ser em gestação: reflexões bioéticas sobre o embrião humano. São Paulo: Loyola, 2002.

BENTO XVI, Papa. Carta Encíclica. Caritas in Veritate. São Paulo: Paulus, 2009. 
BENTO, A. L. Bioética: desafios éticos no debate contemporâneo. São Paulo: Paulinas, 2008.

BARCHIFONTAINE, P. C. Bioética no início da vida. Curitiba: Pistis \& Praxis, n.1, v.2 jan/jun. 2010.

CATECISMO DA IGREJA CATÓLICA. São Paulo: Loyola, 1998.

CIACCIA, C; MATTIOLI, V. O milagre da vida: reflexões de bioética e sobre os direitos do nascituro. Trad. Thereza Christina Stummer. São Paulo: Cidade Nova, 1994.

CIPRIANI, G. O embrião humano: na fecundação, o marco da vida. São Paulo: Paulinas, 2007.

CONSELHO EPISCOPAL LATINO-AMERICANO. Documento de Aparecida. Texto conclusivo da V Conferência Geral do Episcopado Latino-Americano e do Caribe. São Paulo: Paulus, 2007.

DURAND, G. Introdução Geral à Bioética: história, conceitos e instrumentos. Trad. Nicolás Nyimi Campanário. São Paulo: Loyola, 2007.

JOÃO PAULO II, Papa. Carta Encíclica. Evangelium Vitae. São Paulo: Paulinas, 1995.

JUNGES, J. R. Bioética: perspectivas e desafios. São Leopoldo: Unisinos, 1999.

LÉVINAS, E . En découvrant l' existence avec Husserl et Heidegger. Paris: Librairie Philosophique J. Vrin, 1988.

LÉVINAS, E . Le temps et l' autre. Paris: Fata Morgana, 1994.

LÉVINAS, E. Entre nós: ensaios sobre a alteridade. Petrópolis: Vozes, 2010.

LUCAS, L. R. Antropologia y problemas bioéticos. Madrid: Estudios y Ensaios, 2001.

MAÇANEIRO, M. Direitos de vida numa cultura de morte. Revista Eclesiástica Brasileira-REB. Petrópolis: Vozes, n. 209, v.53, p.52-71, mar. 2003.

MARCOTTE, M. L' Overtement libre. Montrial: Bellamin, 1973.

MOSER, A. Biotecnologia e bioética: para onde vamos? Petrópolis: vozes, 2004. 
PESSINI, L. Bioética: um grito por dignidade de viver. São Paulo: Paulinas, 2007.

RAMOS, P. L. D.; LUCATO, C. M. O conceito de pessoa humana. Curitiba: Pistis \& Praxis, n.1, v.2 jan/jun. 2010.

SGRECCIA, E. Manual de bioética: fundamentos e ética biomédica. Trad. Orlando Soares Morais. São Paulo: Loyola, 1996.

SANCHES, A.; SANCHES, C. L. Anterior ao conceito de pessoa: dignidade do embrião como ser humano. Curitiba: Pistis \& Praxis. n.1, v.2 jan/jun. 2010.

SALZANO, F. M \& SCHULER, L. Questões éticas em genética humana. In: De Boni, L. A. Jacob, G. \& Salzan, F. Ética e genética. Porto Alegre: Edipucrs, 1998.

VIDAL, M. O Evangelho da Vida: para uma leitura da Evangelium Vitae. São Paulo: Paulinas, 1998.

Recebido 10/03/2014

Received: 03/10/2014

Aprovado: 24/11/2014 Approved: 11/24/2014 